\title{
PAROUSIA, PEMBENARAN ALLAH, DAN KEBANGKITAN ORANG MATI: PERBUATAN-PERBUATAN BAIK DALAM MERAIH KESELAMATAN MENURUT SURAT-SURAT PAULUS
}

\author{
Demianus Nataniel \\ Sekolah Tinggi Theologia Abdiel \\ demianusnataniel@gmail.com
}

\begin{abstract}
This article focuses on the good works in receiving the salvation in Pauline Letters. It contains of debating on faith and the good works relationship in The New Perspectives on Paul. By exploring some themes relating to Paul's concept of salvation in his Letters, namely: parousia, justification, and the resurrection, this article shows that the good works are essensial part in receiving God's saving work. This conclusion is based on some texts in Pauline Letters that shows Paul's exhortation that asked and urged Christians to do good works in order to welcome parousia.
\end{abstract}

Keywords: good works, justification, parousia, Paul Letters, resurrection, salvation.

\section{Pendahuluan}

Peringatan hari Reformasi beberapa waktu lalu mengingatkan kita antara lain kepada perlawanan Luther terhadap penjualan indulgensi atau surat pengampunan dosa. Di balik praktik penjualan surat pengampunan dosa tersebut terkandung pemahaman bahwa keselamatan dapat diupayakan oleh manusia, bahkan dibeli. Akibatnya, orang-orang miskin menjadi gelisah mengingat ada harga yang harus mereka penuhi untuk meraih keselamatan, padahal mereka hidup dalam keterbatasan. ${ }^{1}$ Di tengah kegelisahan ini Martin Luther mengajarkan bahwa keselamatan adalah anugerah Allah semata, dan bukan hasil usaha manusia. Pengajaran ini terutama didasarkan pada tafsirannya terhadap surat-surat Paulus, khususnya Roma dan Galatia. Di dalamnya Luther memandang gereja saat itu seperti mengikuti pengajaran rabi-rabi Yahudi dan kaum Farisi yang membebani umat dengan menekankan pemberlakuan aturan-aturan dalam hukum Taurat untuk meraih

\footnotetext{
${ }^{1}$ Bnd.. Bernard Kieser, "Melawan Fundamentalisme (Teologi) Katolik: Menemukan Gereja yang
} adalah Peristiwa, dalam Gereja yang Melayani dengan Rendah Hati, peny. E. Martasudjita (Yogyakarta: Kanisius, 2009), 12. 
keselamatan. ${ }^{2}$ Sejak saat itulah doktrin atau ajaran keselamatan karena anugerah semata menjadi bagian penting dalam tradisi protestantisme. Pertanyaannya adalah benarkah Paulus dalam surat-suratnya itu lebih menekankan keselamatan sebagai sebuah anugerah dari Allah yang diterima melalui iman di dalam Yesus Kristus? Jika benar demikian maka dimanakah tempat perbuatan-perbuatan baik?

Dengan mencermati tema-tema yang berhubungan dengan percakapan Paulus mengenai keselamatan dalam surat-suratnya, tulisan ini ingin menunjukkan bahwa Paulus berusaha mengarahkan orang-orang Kristen untuk benar-benar melakukan perbuatanperbuatan baik sebagai unsur yang sangat penting dalam menerima keselamatan di dunia saat ini. Untuk sampai kepada kesimpulan ini maka akan diuraikan tema-tema yang berhubungan dengan percakapan Paulus mengenai keselamatan, yakni: parousia dan penghakiman terakhir, pembenaran Allah, dan kebangkitan orang mati. Sumber pemikiran yang digunakan dalam tulisan ini terutama adalah pandangan dari para pakar dalam The New Perspectives on Paul (NPP). Pilihan atas NPP sebagai sumber rujukan pemikiran didasarkan fakta bahwa kelompok ini muncul sebagai reaksi terhadap pengaruh penafsiran Luther terhadap surat-surat Paulus yang terlanjur dianggap mempertentangkan Injil dengan Taurat, iman dengan perbuatan, kekristenan dengan Yahudi.

\section{Parousia}

Salah satu tema penting berkaitan dengan pemahaman mengenai keselamatan adalah penghakiman terakhir, yang juga berhubungan dengan kedatangan Yesus yang kedua (parousia). Dalam 1 Tesalonika, Paulus secara terbuka menjelaskan keyakinannya bahwa kedatangan Yesus yang kedua akan segera terjadi, dan itu berkaitan dengan Hari Tuhan (1 Tes. 1:10, 2:19, 3:13, 4:14-18, 5:2,23). Istilah parousia sesungguhnya bukanlah khas milik orang-orang Kristen. Istilah ini biasa digunakan dalam konteks politik yang mengacu pada kunjungan para pejabat negara. ${ }^{3}$ Oleh Paulus istilah ini digunakan untuk mengekspresikan keberadaan mereka sebagai sebuah komunitas yang tengah menantikan kedatangan Tuhan, dan bukan kaisar. ${ }^{4}$

\footnotetext{
${ }^{2}$ Bnd. John Lawson, Introduction to Christian Doctrine (Grand Rapids, MI: Francis Asbury, 1986), 224.

${ }^{3}$ Warren Carter, Matthew and Empire: A Sociopolitical and Religious Reading (Maryknoll, NY: Orbis Books, 2000), 39.

${ }^{4}$ Helmut Koester, "Imperial Ideology and Paul's Eschatology in 1 Thessalonians", dalam Paul and Empire: On and Power in Roman Imperial Society, peny. Richard A. Horsley (Harrisburg, PA: Trinity Press University, 1997), 158-159.
} 
Menurut Paulus, Hari Tuhan berarti kedatangan murka Allah, dan orang Kristen adalah orang-orang yang akan diselamatkan dari murka Allah tersebut melalui karya Yesus (1Tes. 1:9-10). Pemahaman mengenai murka Allah ini mendorong Paulus begitu serius untuk menyampaikan nasihat-nasihatnya. ${ }^{5}$ Pemahaman mengenai murka Allah di Hari Tuhan sejalan dengan pemahaman mengenai Hari Tuhan dalam teks-teks Perjanjian Lama. ${ }^{6}$ Di dalamnya, murka Allah dan keselamatan dari Allah akan dinyatakan sesuai dengan apa yang dilakukan oleh Israel. ${ }^{7}$ Oleh sebab itu tuntutan untuk menampilkan kualitas moral yang dapat dipertanggungjawabkan sangat kuat dalam anjuran-anjuran Paulus di surat 1 Tesalonika. Tekanan untuk menampilkan kualitas moral terungkap antara lain dalam frasa "tak bercacat dalam kekudusan" (amemptous en hagiosune) seperti dalam 1 Tesalonika 3:13. Kata amemptous juga muncul dalam 1 Tesalonika 2:10 dan 5:23. Dengan kata lain, dalam 1 Tesalonika, Paulus memang benar-benar mendorong jemaat di Tesalonika untuk memerhatikan perilaku yang berkualitas. Gagasan seperti ini juga muncul dalam 1 Korintus 1:8-9. Di dalamnya Paulus mengingatkan pentingnya kualitas moral orang-orang Kristen dalam menantikan kedatangan Tuhan. ${ }^{8}$ Persoalan yang penting untuk dicermati dalam menunjukkan kualitas moral adalah bagaimana jemaat dapat mengatasi perselisihan seperti yang terungkap dalam 1 Korintus $1: 11 .{ }^{9}$

Berkaitan dengan penghakiman terakhir, beberapa bagian dari tulisan Paulus yang perlu dicermati adalah surat 1 Korintus 3:5-4:5; 5:1-5; 6; 10; 11:27-34; 2 Korintus 5:10, dan Galatia 5:16-6:10. Berdasarkan penafsiran terhadap teks-teks itu, Van Landingham menyimpulkan bahwa perbuatan seseorang menjadi kriteria utama dalam penghakiman terakhir. ${ }^{10}$ Menurutnya, tidak ada satu teks pun di antara surat-surat Paulus, kecuali 1 Korintus 1:8, yang menyatakan secara positif mengenai perbuatan baik yang menghasilkan keuntungan di saat penghakiman terakhir. ${ }^{11}$ Hampir semua teks menyatakan secara negatif mengenai ketidaktaatan yang membawa kepada penghukuman di saat penghakiman

\footnotetext{
${ }^{5}$ Chris Van Landingham, Judgement and Justification in Early Judaism and the Apostle Paul (Peabody, MA: Hendrickson, 2006), 177.

${ }^{6}$ Ibid.

${ }^{7}$ Ibid.

${ }^{8}$ Ibid.

${ }^{9}$ Michael R. Cosby, Apostle on the Edge: An Inductive Approach to Paul (Louisville, KY: Westminster John Knox Press, 2009), 144.

${ }^{10}$ Landingham, Judgement and Justification, 198-199.

${ }^{11}$ Ibid., 198.
} 
terakhir. ${ }^{12}$ Artinya, menurut Van Landingham, Paulus secara meyakinkan berpandangan bahwa ada kemungkinan orang-orang Kristen ditolak akibat kegagalan moralitas mereka. ${ }^{13}$

Persoalannya ialah jika apa yang dipahami oleh Van Landingham memang benar, maka Allah dapat dipahami memberi tempat bagi adanya orang-orang yang akan mendapatkan hukuman. Berkenaan dengan hal ini penulis setuju dengan pemahaman Jan Bonda, bahwa sebagaimana dalam Perjanjian Lama, Paulus juga tidak menempatkan Allah sebagai sosok yang mengharapkan adanya orang-orang yang menerima hukuman di hari penghakiman. ${ }^{14}$ Untuk apa Allah menciptakan manusia kalau sebagian di antaranya, atau bahkan mungkin sebagian besar di antaranya memang disiapkan untuk mendapatkan hukuman? Sebaliknya, Allah mengharapkan setiap manusia mendapatkan keselamatan sebagaimana pernyataan Paulus yang mengharapkan seluruh Israel mendapatkan keselamatan (Rm. 11:26). Walaupun yang disebutnya adalah Israel, tapi konteks percakapannya berhubungan dengan relasi dan keselamatan bagi Israel dan bangsa-bangsa lain.

Dalam Roma 2:6-10, Paulus memang menjelaskan bahwa Allah akan membalaskan setiap perbuatan manusia. Allah akan memberikan hidup kekal bagi yang berbuat baik, tetapi penderitaan dan kesesakan akan menimpa setiap orang yang berbuat jahat, baik orang Yahudi maupun orang Yunani. Pertanyaannya adalah: apakah dengan demikian Paulus berharap ada orang-orang yang terus berbuat jahat, yang pada gilirannya akan menerima hukuman dari Allah? Anjuran-anjuran untuk hidup dalam kekudusan dan menampilkan perbuatan-perbuatan baik yang ditekankan oleh Paulus jelas menunjukkan harapannya agar tidak ada pihak yang akan menerima hukuman Allah. Gagasan ini juga terekam dalam tulisan deutero Paulus, yakni 1 Timotius 2:1-4,

Besar kemungkinan bahwa penjelasan-penjelasan Paulus tentang hari Tuhan dan penghakiman Allah adalah bagian dari retorikanya dalam meyakinkan jemaat-jemaat untuk hidup kudus dan benar, bukan semata-mata meraih kehidupan setelah penghakiman nanti, tetapi saat itu juga. Itulah sebabnya Paulus meyakinkan bahwa keselamatan itu bukan belum terjadi, tetapi sudah dimulai, dan tengah mencapai kesempurnaannya. Bagi Paulus keselamatan bukanlah sesuatu yang masih dikejar, tetapi yang sudah ada dan harus dijalani sebagaimana anjurannya untuk mengerjakan keselamatan dalam Filipi 2:12.

\footnotetext{
12 Ibid.

${ }^{13}$ Ibid., 199.

${ }^{14}$ Jan Bonda, The One Purpose of God: An Answer to the Doctrine of Eternal Punishment (Grand Rapids, MI \& Cambridge,UK: William B. Eerdmans, 1993), 246.
} 


\section{Pembenaran Allah}

Upaya Paulus untuk menekankan kualitas moral dalam perbuatan orang-orang Kristen sebagai yang harus dipenuhi dalam meraih keselamatan juga terlihat dalam perdebatan para ahli mengenai pembenaran Allah. Salah satu perdebatan berkenaan dengan pembenaran Allah adalah adanya kesan kontradiktif antara Roma 2:6 yang menyatakan bahwa Allah akan membalas (apodōsei) setiap orang setimpal dengan perbuatannya, dengan Roma 3:20 yang menyatakan bahwa tidak ada seorang pun yang dapat dibenarkan (dikaīothētai) di hadapan Allah oleh karena melakukan hukum Taurat.

Mereka yang berpandangan bahwa keselamatan merupakan anugerah Allah semata akan menjelaskan bahwa Roma 2 lebih bersifat hipotetis, yakni menggambarkan sesuatu yang ideal, tetapi dalam kenyataannya tidak demikian. ${ }^{15}$ Sementara Barth dan Calvin lebih memahaminya sebagai cara Paulus mengajak orang-orang Kristen untuk mengarahkan diri pada kekuasaan Allah. ${ }^{16}$ Sebaliknya Van Landingham menolaknya dengan menyatakan bahwa pendapat tersebut sulit dipertahankan karena tema penghakiman berdasarkan tindakan diulangi lagi dalam Roma $6: 16 ; 8: 13 ; 14: 10-12 .{ }^{17}$ Menurutnya ada kesesuaian antara pemikiran Paulus dengan pemikiran Yudaisme di masa Bait Allah kedua mengenai keselamatan kekal berdasarkan tindakan. ${ }^{18}$

Van Landingham mendasari pendapatnya dengan menelusuri kisah pemilihan Allah terhadap Israel dalam Kejadian 12, 15 dan 17. Teks-teks tersebut memang tidak jelas mengungkap alasan mengapa Allah memanggil Abraham, yang diteruskan dengan perjanjian Allah dan Israel. Teks-teks tersebut, khususnya Kejadian 15 dan 17, lebih mengungkapkan keharusan bagi Israel untuk setia menaati kewajiban-kewajiban moral sebagai konsekuensi perjanjian dengan Allah. Namun demikian, di dalam teks-teks itu juga tidak ditemukan bukti bahwa pemilihan Allah terhadap Israel adalah keputusan Allah tanpa syarat. Sebaliknya, berdasarkan beberapa literatur Yudaisme di luar Perjanjian Lama, yakni Jubelees, tulisan-tulisan Philo, Pseudo-Philo, Flavius Josephus dan Apocalypse of Abraham, Van Landingham menyimpulkan bahwa Allah memilih Abraham untuk kemudian mengikat perjanjian dengannya karena Abraham memiliki kualitas hidup yang 90.

${ }^{15}$ F.F.Bruce, The Epistle of Paul to the Romans (Grand Rapids, MI: William B. Eerdmans, 1963),

${ }^{16}$ Karl Barth, The Epistle to the Romans, terj. oleh Edwyn C. Hoskyns (London/ Oxford/ New York: Oxford University Press, 1980), 61-63. John Calvin, Commentaries on the Epistle of Paul the Apostle to the Romans, terj. \& peny. John Owen (Grand Rapids, MI: Williamm. B. Eerdmans, 1946), 89.

${ }^{17}$ Landingham, Judgement and Justification, 215-216.

${ }^{18}$ Dengan pola yang sama para pendukung keselamatan sebagai anugerah Allah semata juga menyatakan bahwa pemikiran Paulus ini sama dengan pemikiran tradisional Yudaisme yang ada pada waktu itu. C.H. Dodd, The Epistle Paul to the Romans (London: Hodder \& Stoughton Limited, 1947), 33. 
layak untuk dipilih dan diberkati. Contohnya adalah salah satu teks dalam Jubilees dan Apocalypse of Abraham yang mengangkat keberanian Abraham dalam melecehkan patungpatung berhala milik ayahnya sebelum Allah memanggil dan mengikat perjanjian dengannya. ${ }^{19}$

Berkenaan dengan adanya kesan kontradiktif Roma 2:6 dengan Roma 3:20, penulis setuju dengan pandangan Van Landingham tentang kesinambungan Roma 2 dan 3. Ia menjelaskan bahwa kesinambungan pemahaman Roma 2 dengan Roma 3 akan dapat ditemukan ketika kita memahami Roma 2 dan 3 berada dalam konteks retorika Paulus untuk menunjukkan kelayakan orang-orang bukan Yahudi dalam meraih keselamatan melalui perbuatan yang dituntun oleh iman di dalam Yesus Kristus. ${ }^{20}$ Dengan iman, orangorang bukan Yahudi mampu melakukan perbuatan-perbuatan yang baik.

Perbuatan-perbuatan yang baik di sini tentu saja berhubungan dengan aturan-aturan dalam hukum Taurat, yang juga menekankan kualitas moral dalam kehidupan manusia. Dengan demikian, jelas yang penting bukanlah mereka yang mendengar tetapi yang melakukan hukum Taurat (ayat 13). Hal ini berbeda dengan yang dimaksud dalam Roma 3:20. Hukum taurat yang dimaksud dalam Roma 3:20 bukanlah dalam arti seluruh aturan yang mencerminkan kualitas moral seseorang, melainkan hanya menunjuk pada hal-hal berkenaan dengan identitas Yahudi, khususnya tradisi sunat. Di sini Paulus sedang ingin menjelaskan bahwa keselamatan tidak terletak pada apakah dia Yahudi atau bukan Yahudi, disunat atau tidak disunat, tetapi pada perbuatannya yang dipimpin oleh Roh Kudus.

Pandangan bahwa tema pembenaran dalam surat-surat Paulus adalah sebuah retorika dalam menghadapi musuh-musuhnya juga dimiliki oleh Campbell. Berdasarkan telaah semantik dan kunci pemahaman kristologis terhadap penggunaan dikaiosune theou oleh Paulus, khususnya dalam Roma 1:17 dan 3:21-26, Campbell berpendapat bahwa penggunaan frasa dikaiosunē theou dalam surat-surat Paulus lebih merupakan sebuah retorika dalam melawan pandangan yang menekankan tindakan Allah yang bersifat retributif. ${ }^{21}$ Pandangan Campbell ini tampaknya sejalan dengan pemahaman Dunn yang juga menelaah makna "dibenarkan oleh Allah". Dengan terlebih dahulu mengangkat pergeseran yang dinilai negatif dari kata-kata "dibenarkan oleh Allah" menjadi "dibenarkan oleh iman" dalam konteks bagaimana meraih keselamatan, serta penekananpenekanan yang keliru mengenai makna "dibenarkan oleh Allah", Dunn menunjukkan

\footnotetext{
${ }^{19}$ Landingham, Judgement and Justification, 23-24, 34-35.

${ }^{20}$ Ibid., 240.

${ }^{21}$ Douglas A. Campbell, The Deliverance of God: An Apocalyptic Rereading of Justification in
} Paul (Grand Rapids, MI \& Cambridge, UK: William B. Eerdmans Publishing Company, 2009), 704-710. 
beberapa kata penting untuk memahami kata-kata "dibenarkan oleh Allah" dalam suratsurat Paulus. $^{22}$

Penekanan keliru yang pertama menurut Dunn adalah pemahaman yang terlalu menekankan keselamatan jiwa, atau aspek batin manusia secara pribadi. ${ }^{23}$ Kekeliruan yang kedua adalah pemahaman yang menempatkan Yudaisme sebagai yang berseberangan dalam hal meraih keselamatan, yang pada akhirnya muncul sikap orang Kristen yang melecehkan makna kehadiran agama-agama lain. ${ }^{24}$

Untuk memahami dengan baik makna "dibenarkan oleh Allah", Dunn menunjukkan tiga kata yang perlu diperhatikan dalam surat-surat Paulus. Pertama adalah kata zēlos yang diterjemahkan antara lain dengan kata "rajin" atau "sungguh-sungguh giat", atau zeal dalam Galatia 1:14, Filipi 3:5-6 dan Roma 10:3. ${ }^{25}$ Kata tersebut menampilkan semangat Paulus untuk menjaga kemurnian ajaran agama sebagaimana teksteks Perjanjian Lama yang menekankan Allah yang cemburu. ${ }^{26}$ Itu juga yang ditampilkan para martir dalam Yudit dan Jubilees, dan teks-teks Perjanjian Lama, serta Mishnah. ${ }^{27}$ Paulus berada dalam tradisi holy zeal. ${ }^{28}$

Kata yang kedua adalah kauchēsis atau "bermegah" (boasting). Allah baginya adalah Allah bagi Israel, namun kemudian terjadi perubahan sikap "bermegah" dengan memahami bahwa Allah juga milik orang bukan Yahudi. ${ }^{29}$ Kata penting yang ketiga adalah melakukan hukum Taurat. ${ }^{30}$ Kata ini muncul dalam konteks perdebatan mengenai sunat dan makan-makanan yang diharamkan, bukan keseluruhan dari Taurat itu sendiri. ${ }^{31}$ Dengan menyimak konteks pergumulan Paulus, maka seperti juga Campbell, Dunn menyimpulkan bahwa kata-kata tersebut digunakan Paulus untuk melawan musuhmusuhnya.

Berdasarkan penjelasan Landingham, Dunn, serta Campbell sebagaimana dipaparkan di atas maka dapat disimpulkan bahwa ketiganya sama-sama menempatkan tema pembenaran dalam surat Roma sebagai bagian dari retorika Paulus dalam melawan musuh-musuhnya. Pertanyaannya ialah musuh yang mana yang disasar oleh Paulus?

\footnotetext{
22 James D. G. Dunn, The New Perspectives on Paul (Grand Rapids, MI \& Cambridge, UK: William B. Eerdmans, 2008), 193-211.

${ }^{23}$ Ibid., 195-196.

${ }^{24}$ Ibid.,197-199.

${ }^{25}$ Ibid., 200-204.

${ }^{26}$ Ibid., 202.

${ }^{27}$ Ibid.

${ }^{28}$ Ibid.

${ }^{29}$ Ibid., 202-203.

${ }^{30}$ Ibid., 203.

31 Ibid.
} 
Benarkah musuh yang dimaksud adalah orang-orang yang berpandangan tentang tindakan Allah yang bersifat retributif?

Untuk menjawab pertanyaan di atas maka setidaknya ada dua hal yang perlu dicermati. Yang pertama berkaitan dengan waktu dan tempat Paulus dalam menulis surat Roma. Berdasarkan catatan Kisah Para Rasul, serta penjelasan dalam Roma 1:8,10 maka Paulus tampaknya belum pernah berhadapan langsung atau tinggal dengan jemaat di Roma. Rasanya terlalu berlebihan jika Paulus yang tidak memiliki andil langsung dalam pembangunan jemaat di Roma, berusaha mempersoalkan gagasan-gagasan yang muncul, atau yang dibawa oleh para musuhnya kepada jemaat di Roma. Belum lagi jika menyimak bagaimana penuturan Paulus yang tidak terlalu emosional seperti surat-suratnya kepada jemaat Korintus, Galatia, dan Filipi.

Kedua, mengingat percakapan Paulus dalam surat Roma banyak menyebut orangorang Yahudi dalam bentuk orang ketiga jamak maka besar kemungkinan bahwa Paulus sedang membayangkan para penerima suratnya sebagai orang-orang bukan Yahudi. Oleh sebab itu penting untuk memahami gambaran umum masyarakat kota Roma terhadap orang-orang Yahudi. Salah satu catatan penting berkenaan dengan keberadaan orang-orang Yahudi di kota Roma adalah peristiwa pengusiran orang-orang Yahudi dari kota Roma pada tahun $52 \mathrm{ZB} .{ }^{32}$ Situasi ini dapat mencerminkan adanya pandangan buruk masyarakat di kota Roma, termasuk orang-orang Kristen, kepada orang-orang Yahudi. ${ }^{33}$ Hal ini mungkin diketahui oleh Paulus, dan membuat Paulus berusaha untuk mengantisipasi sikapsikap buruk yang muncul dari kalangan jemaat di Roma yang bukan Yahudi, kepada orang-orang Yahudi. ${ }^{34}$ Artinya, melalui surat Roma, termasuk penjelasannya tentang pembenaran Allah, Paulus berusaha melindungi orang-orang Yahudi dari kemungkinan adanya perlakuan buruk dari orang-orang-orang bukan Yahudi. ${ }^{35}$

Lalu apa hubungan antara tema pembenaran Allah dengan upaya melindungi orangorang Yahudi? Salah satu cara ampuh untuk melerai orang yang tengah bertikai untuk tidak menyakiti lawannya adalah dengan meyakinkan masing-masing pihak bahwa yang sedang melerai bukanlah musuh. Itulah yang dilakukan oleh Paulus. Dengan menunjukkan kelemahan pemikiran orang-orang Yahudi tentang jalan keselamatan, dan dengan menempatkan Allah pada posisi yang mengatasi segalanya, Paulus berusaha meyakinkan

\footnotetext{
${ }^{32}$ Neil Elliott, "Romans 13:1-7 in the Context of Imperial Propaganda", dalam Paul and Empire: On and Power in Roman Imperial Society, peny. Richard A. Horsley (Harrisburg, PA: Trinity Press International, 1997), 190.

33 Ibid.

34 Ibid.

35 Ibid.
} 
jemaat di Roma bahwa dirinya berada di pihak mereka. Namun demikian berdasarkan posisi itulah Paulus meminta agar jemaat di Roma tidak semena-mena terhadap orangorang Yahudi. Dengan kata lain, tema pembenaran Allah dalam surat Roma adalah bagian dari retorika Paulus bukan dalam rangka melawan musuh-musuhnya, melainkan dalam rangka membesarkan hati orang-orang Kristen di Roma untuk tidak memperlakukan orangorang Yahudi dengan semena-mena.

\section{Kebangkitan Orang Mati}

Pandangan Paulus mengenai pentingnya menjalani hidup dengan kualitas moral tertentu berkenaan dengan keselamatan tidak akan lengkap tanpa membahas pandangannya terhadap kebangkitan, khususnya dalam 1 Korintus 15. Tema umum dari 1 Korintus 15 adalah kebangkitan. O’Connor menjelaskan bahwa walaupun bagian ini ditempatkan pada bagian akhir, tetapi bukan berarti tidak penting. ${ }^{36}$ Para orator ulung biasanya menempatkan hal-hal yang dianggap penting pada bagian awal atau akhir dari percakapannya. ${ }^{37}$ Pemahaman ini sejalan dengan pendapat Harris yang menyatakan bahwa dalam 1 Korintus 15 tergambar keterampilan Paulus beretorika dengan memanfaatkan sumber-sumber yang diketahuinya untuk menjelaskan kebangkitan orang mati. ${ }^{38}$

Dalam 1 Korintus 15:1-11, Paulus menyinggung sebuah tradisi mengenai kematian dan kebangkitan Kristus, yang disebutnya sesuai dengan pemberitaan Kitab Suci (ayat 34). Tradisi yang dipakai oleh Paulus ini merupakan sebuah pengakuan iman yang penting dari gereja perdana pada waktu itu. ${ }^{39}$ Lalu ia pun menyinggung peristiwa penampakan Yesus setelah kebangkitan. Paulus menuturkan bagaimana Yesus menampakkan diri mulai dari yang pertama kepada Kefas, kemudian kepada kedua belas murid, hingga sampai kepada dirinya (ayat 5-7). Penjelasannya ini tampaknya merupakan bagian dari upaya Paulus untuk meyakinkan jemaat di Korintus mengenai kerasulannya yang didukung dengan peristiwa penampakan Yesus terhadap dirinya. ${ }^{40}$ Posisinya dalam hal ini sama seperti rasul-rasul lainnya yang juga menerima penampakan Yesus. ${ }^{41}$

\footnotetext{
36 Jerome Murphy-O’Connor," 1 and 2 Corinthians”, dalam The Cambridge Companion to St. Paul, peny. James D. G. Dunn (New York: Cambridge University Press, 2004), 82.

${ }^{37}$ Ibid.

${ }^{38}$ Geoffrey Harris, Paul (London: SCM Press, 2009), 127.

${ }^{39}$ Ibid.

${ }^{40}$ Herman Ridderbos, Paul: An Outline of His Theology, terj. John Richard De Witt (Grand Rapids, MI \& Cambridge, UK.:William B. Eerdmans, 1977), 449.

${ }^{41}$ Ibid.
} 
Setelah menampilkan kewibawaan sebagai seorang rasul berdasarkan pengalaman spiritualnya bersama Yesus, Paulus mulai menjawab persoalan yang ada di jemaat saat itu, yakni adanya orang-orang yang menyangkal adanya kebangkitan orang mati (ayat 12). Masyarakat Greko-Romawi umumnya lebih meyakini adanya kekekalan jiwa, tetapi tidak dengan kebangkitan orang mati. ${ }^{42}$ Berdasarkan prinsip kekekalan jiwa maka reinkarnasi jauh lebih dapat diterima daripada kebangkitan orang mati. ${ }^{43}$ Kalangan Yahudi yang tidak mempercayai kebangkitan adalah kaum Saduki, sedangkan di kalangan masyarakat GrekoRomawi yang jelas menolak adanya kebangkitan orang mati adalah kaum Epikuros. ${ }^{44}$

Berdasarkan tradisi yang sudah dipahami oleh orang-orang Kristen di Korintus tentang kebangkitan Kristus maka Paulus mempertentangkan konsekuensi orang-orang yang percaya adanya kebangkitan dengan yang tidak percaya (12-28). Jika keyakinan orang-orang yang tidak percaya kepada kebangkitan benar maka kebangkitan Kristus pun tidak pernah terjadi. Jika kebangkitan Kristus tidak pernah terjadi maka tidak akan terjadi perubahan apa-apa, termasuk tidak ada anugerah Roh yang selama ini dibanggakan oleh orang-orang Kristen di Korintus. ${ }^{45}$ Sebaliknya, jika Paulus dan orang-orang yang percaya akan kebangkitan adalah benar maka kebangkitan yang Kristus alami akan memengaruhi dan memberikan kekuatan bagi mereka. Maut tidak lagi berkuasa atas mereka, dan kematian bukanlah akhir segalanya. ${ }^{46}$ Melalui penjelasannya ini, Paulus tentu tidak bermaksud menyatakan adanya dua kemungkinan kebenaran, yakni adanya kebangkitan atau tidak ada kebangkitan. Kebenaran bagi Paulus dalam hal kebangkitan adalah satu, yakni bahwa kebangkitan itu benar-benar harus diyakini akan terjadi. Alasannya ialah karena Kristus telah dibangkitkan, dan banyak orang menjadi saksinya, termasuk dirinya sendiri.

Wright mengatakan bahwa penjelasan Paulus tentang kebangkitan orang mati dalam 1 Korintus 15 harus dipahami berdasarkan Kejadian 1-3. ${ }^{47}$ Dengan merujuk pada Kejadian 3, Paulus di ayat 21-22 menjelaskan bahwa kematian datang melalui satu orang, demikian juga dengan kebangkitan yang datang melalui satu orang juga. ${ }^{48}$ Sebagaimana di dalam Adam semua orang akan mati maka di dalam Kristus semua akan hidup. Artinya,

\footnotetext{
${ }^{42}$ Michael R. Cosby, Apostle on the Edge: An Inductive Approach to Paul (Louisville-Kentucky: Westminster John Knox Press, 2009), 147.

43 Ibid.

${ }^{44}$ Brevard S. Childs, The Church's Guide for Reading Paul: The Canonical Shaping of the Pauline Corpus (Grand Rapids, Michigan/ Cambridge, UK: William B. Eerdmans Publishing Co., 2008), 87.

${ }^{45}$ O’Connor, "1 and 2 Corinthians", 82.

46 Ibid.

${ }^{47}$ N.T. Wright, Paul (Minneapolis: Fortress Press, 2005), 28.

48 Ibid.
} 
menurut Wright, ini adalah sebuah pernyataan Paulus tentang ciptaan baru yang terjadi melalui Kristus. ${ }^{49}$ Pernyataan bahwa ciptaan baru terjadi melalui Kristus dinyatakan oleh Paulus dengan merujuk pada Mazmur 8, yang diyakini berhubungan dengan kisah penciptaan dalam Kejadian 1. ${ }^{50}$ Rujukan kepada Mazmur 8 yang berkaitan dengan kisah penciptaan dalam Kejadian 1 inilah yang melatarbelakangi penjelasan Paulus dalam 1 Korintus 15:42-49 tentang bagaimana wujud kebangkitan. ${ }^{51}$ Dengan menyimak pandangan Wright maka rujukan Paulus terhadap kisah penciptaan dalam penjelasannya mengenai wujud kebangkitan menunjukkan bahwa kebangkitan bagi Paulus berkaitan dengan pemulihan ciptaan.

Penjelasan Paulus tentang wujud kebangkitan orang mati berdasarkan kebangkitan Yesus tampaknya mencerminkan adanya perbedaan gagasan eskatologi apokaliptik Paulus dengan gagasan eskatologi apokaliptik Yahudi, khususnya yang dimiliki oleh orang-orang Farisi pada waktu itu. ${ }^{52}$ Namun demikian keduanya mengaitkannya dengan keyakinan adanya kebangkitan orang-orang mati di akhir zaman. ${ }^{53}$ Horsley berkeyakinan bahwa penjelasan Paulus tentang kebangkitan orang mati dalam 1 Korintus 15 merupakan bagian dari perlawanannya terhadap kekaisaran Romawi, sebagaimana pandangan kaum Farisi pada waktu itu. ${ }^{54}$ Di dalamnya terdapat tiga motif yang saling berkaitan, yakni ganjaran bagi kematian para martir, campur tangan dan tindakan Allah terhadap para penguasa yang lalim, serta pembaharuan kondisi sosial, politik dan keagamaan bangsa Israel. ${ }^{55}$

Perlawanan Paulus terhadap imperium Romawi juga tercermin dari perbedaan antara gagasan yang terkandung dalam penjelasan Paulus tentang kebangkitan orang mati dengan gagasan yang tidak hanya terkait kekekalan jiwa yang umumnya diyakini oleh masyarakat Greko-Romawi, tetapi juga dengan gagasan eskatologi imperium Romawi. ${ }^{56}$ Eskatologi imperium Romawi menempatkan kaisar sebagai yang akan membawa dunia kepada zaman keemasan melalui kekuatan militer dan kekuasaan kaisar. ${ }^{57}$ Bagi Paulus, pembawa perubahan bukanlah kaisar, tetapi Allah melalui Kristus. Bukan juga melalui kekerasan dan kekuatan militer, tetapi melalui kematian dan kebangkitan Kristus.

\footnotetext{
49 Ibid.

${ }^{50}$ Ibid.

${ }^{51}$ Ibid.

52 John D. Crossan \& Jonathan L. Reed, In Search of Paul: How Jesus's Apostle Opposed Rome's Empire with God's Kingdom (NY: Harper Collins Publishers, 2005), 129, 345.

${ }^{53}$ Ibid.

${ }^{54}$ Richard A. Horsley, "Rhetoric and Empire-and 1 Corinthians", dalam Paul and Politics, peny. Richard A. Horsley, 99-100.

55 Ibid., 98.

${ }^{56}$ John D. Crossan \& Jonathan L. Reed, In Search of Paul, 129, 344.

${ }^{57}$ Ibid., 129.
} 
Selain berkaitan dengan pemulihan ciptaan, penjelasannya mengenai kebangkitan digunakan oleh Paulus sebagai landasan hidup orang-orang Kristen yang telah mengalami pembaharuan, dan tidak lagi hidup di bawah kuasa dosa (ayat 50-57). Itulah sebabnya di ayat 58 Paulus memberikan nasihat agar orang-orang Kristen berdiri teguh dan tidak goyah, tetapi juga giat dalam pekerjaan Tuhan. Berdasarkan tema-tema sebelumnya dalam surat 1 Korintus maka bisa jadi yang dimaksudkan adalah agar orang-orang Kristen memiliki keyakinan yang teguh tentang injil yang Paulus beritakan, yakni bahwa Yesus adalah mesias yang disalibkan. Bagi orang-orang Yunani berita itu adalah kebodohan, dan bagi orang-orang Yahudi itu adalah batu sandungan, tetapi bagi orang-orang Kristen itu adalah kekuatan Allah (1 Kor.1:18-24). Berdasarkan keyakinan tersebut maka orang-orang Kristen dipanggil untuk giat dalam pekerjaan Tuhan.

Dalam 1 Korintus 16:10, pekerjaan Tuhan dikaitkan dengan apa yang dilakukan oleh Timotius. Sebagai rekan sekerja Paulus, Timotius tidak hanya bersama-sama Paulus mewartakan Injil, tetapi juga membuat relasi dan komunikasi antara Paulus dengan jemaatjemaat yang dibinanya tetap terjaga. Dua hal yang dikerjakan oleh Paulus ini tidak dapat dipisahkan, karena Injil Kristus yang dimaksud oleh Paulus juga adalah bentuk kehidupan yang dianugerahkan Allah sebagaimana tercermin dalam Galatia 3:28. "Dalam hal ini tidak ada orang Yahudi atau orang Yunani, tidak ada hamba atau orang merdeka, tidak ada lakilaki atau perempuan, karena kamu semua adalah satu di dalam Kristus Yesus.”

Inilah Injil yang diberitakan oleh Paulus, yakni kematian dan kebangkitan Kristus yang mempersatukan umat manusia yang terkotak-kotak akibat kuasa dosa yang membelenggu. Oleh sebab itu benar apa yang dikatakan oleh Tambasco yang berpendapat bahwa bagi Paulus tujuan dari seluruh karya Allah melalui kematian dan kebangkitan Yesus, serta dicurahkan-Nya Roh Kudus adalah rekonsiliasi, yakni pemulihan relasi yang rusak antara manusia dengan Allah, serta manusia dengan ciptaan Allah lainnya. ${ }^{58}$ Inilah juga yang diperjuangkan baik oleh Paulus maupun oleh komunitas-komunitas Kristen perdana yang sejalan dengannya, yakni dengan menolak semua bentuk diskriminasi atau pembedaan perlakuan terhadap sesama manusia atas dasar apapun. Oleh sebab itu dapatlah dimengerti mengapa Paulus begitu keras bersikap terhadap orang-orang Yahudi yang bermegah karena kondisi keyahudiannya sebagaimana tercermin dari kalimatnya yang terdengar kasar terhadap lawan-lawannya (Gal. 2:13; Flp. 3:2).

${ }^{58}$ Anthony J. Tambasco, A Theology of Atonement and Paul's Vision of Christianity (Collegeville, MN: The Liturgical Press, 1991), 112. 
Dari seluruh uraian di atas maka dapat disimpulkan bahwa percakapan Paulus tentang kebangkitan orang mati dalam 1 Korintus 15 tidak semata-mata berbicara mengenai kebangkitan itu sendiri. Penjelasan Paulus sebagai seorang dari golongan Farisi tampaknya menjadi bagian dari upayanya untuk melawan kekuasaan Romawi. Di satu sisi Paulus memang meyakini akan adanya kebangkitan orang mati, namun demikian bagi Paulus yang lebih penting bukanlah bagaimana bentuk atau wujud kebangkitan itu sendiri melainkan bagaimana orang-orang Kristen menjalani hidup di dunia ini sebagai pernyataan hidup yang telah diselamatkan. Dalam hal ini orang-orang Kristen dipanggil untuk menampilkan kehidupan yang memenuhi standar tertentu, yang dapat dikategorikan sebagai perbuatan-perbuatan baik.

\section{Kesimpulan}

Berdasarkan uraian mengenai tema-tema yang berhubungan dengan keselamatan dalam surat-surat Paulus, khususnya yang bersumber dari pemikiran pakar dalam NPP maka setidaknya ada dua hal yang dapat disimpulkan berkenaan dengan pentingnya perbuatan-perbuatan baik dalam pemikiran Paulus. Pertama, dari tema-tema yang berhubungan dengan percakapan Paulus mengenai keselamatan terlihat pentingnya perbuatan-perbuatan baik. Untuk menyambut kedatangan Hari Tuhan yang juga dipahami sebagai hari penghakiman maka orang-orang Kristen dipanggil untuk menampilkan cara hidup yang memenuhi standar moral tertentu agar mereka tidak kedapatan bercacat dan bercela di hari penghakiman.

Berkaitan dengan tema pembenaran, pentingnya perbuatan-perbuatan baik untuk meraih keselamatan semakin ditegaskan oleh Van Landingham yang menekankan bahwa justeru perbuatan-perbuatan baiklah yang menjadi dasar keputusan Allah dalam penghakiman terakhir. Artinya, menurut Van Landingham, Paulus tidak memahami sama sekali keselamatan yang diterima melalui iman yang dianugerahkan Allah tanpa syarat sebagaimana pandangan Luther dan para penerusnya. Namun demikian, terlepas dari perdebatan yang masih tetap hangat mengenai relasi iman dan perbuatan di kalangan pakar dalam NPP, mereka sepakat bahwa perbuatan-perbuatan baik merupakan unsur penting dalam menunjukkan cara hidup orang-orang yang diselamatkan.

Kedua, berkenaan dengan penekanan atas perbuatan-perbuatan baik sebagai bagian penting dalam meraih atau menampilkan cara hidup orang-orang yang diselamatkan, para pakar umumnya sepakat meyakini bahwa Paulus lebih mengarahkan orang-orang Kristen 
untuk memperhatikan kehidupan di dunia ini dan bukan di alam baka nanti. Walaupun Paulus juga menegaskan pentingnya kepercayaan akan kebangkitan orang mati, percakapannya tersebut bukan mengarahkan umat untuk lebih mementingkan kehidupan setelah kematian nanti, melainkan untuk mendorong orang-orang Kristen lebih memperhatikan perilaku keseharian mereka di dunia ini, termasuk mengupayakan berbagai perubahan terkait situasi dan kondisi Israel di bawah di bawah pemerintahan Romawi.

Dari dua kesimpulan sebagaimana disebutkan di atas maka benar apa yang dikatakan dalam Yakobus 2:20, bahwa iman tanpa perbuatan adalah iman yang kosong. Kepercayaan gereja kepada Yesus Kristus sebagai Tuhan dan Juruselamat harus dinyatakan melalui serangkaian perbuatan-perbuatan baik, yang tujuannya adalah perubahan dalam kehidupan sosial dan politik masyarakat tempat gereja hadir saat ini. Penekanan surat-surat Paulus tentang pentingnya memperhatikan kehidupan di dunia saat ini bukan semata-mata mendorong gereja mengabaikan segala sesuatu berkenaan dengan akhir zaman. Sebaliknya gereja dipanggil untuk benar-benar memperhatikan kembali tanda-tanda akhir zaman bukan dengan melarikan diri dari tanggung jawab untuk memperbaharui kehidupan sosial masyarakatnya, atau lebih asyik dengan dirinya sendiri, tetapi dengan bersungguh-sungguh memulihkan segala kerusakan yang ada di tengahtengah masyarakat supaya pada saatnya gereja tidak kedapatan bercacat dan bercela.

\section{Kepustakaan}

Barth, Karl. The Epistle to the Romans, terj. oleh Edwyn C. Hoskyns. London/ Oxford/ New York: Oxford University Press, 1980.

Bonda, Jan. The One Purpose of God: An Answer to the Doctrine of Eternal Punishment. Grand Rapids, MI \& Cambridge, UK: William B. Eerdmans, 1993.

Bruce, F.F. The Epistle of Paul to the Romans. Grand Rapids, MI: William B. Eerdmans, 1963.

Calvin, John. Commentaries on the Epistle of Paul the Apostle to the Romans, terj. \& peny. John Owen. Grand Rapids, MI: Williamm. B. Eerdmans, 1946.

Campbell, Douglas A. The Deliverance of God: An Apocalyptic Rereading of Justification in Paul. Grand Rapids, MI \& Cambridge, UK: William B. Eerdmans Publishing Company, 2009.

Carter, Warren. Matthew and Empire: A Sociopolitical and Religious Reading. Maryknoll, NY: Orbis Books, 2000.

Childs, Brevard S. The Church's Guide for Reading Paul: The Canonical Shaping of the Pauline Corpus. Grand Rapids, Michigan/ Cambridge, UK: William B. Eerdmans Publishing Co., 2008. 
Cosby, Michael R. Apostle on the Edge: An Inductive Approach to Paul. Louisville, KY: Westminster John Knox Press, 2009.

Crossan, John D. \& Reed, Jonathan L. In Search of Paul: How Jesus's Apostle Opposed Rome's Empire with God's Kingdom. NY: Harper Collins Publishers, 2005.

Dodd, C.H. The Epistle Paul to the Romans. London: Hodder \& Stoughton Limited, 1947.

Dunn, James D. G. The New Perspectives on Paul. Grand Rapids, MI \& Cambridge, UK: William B. Eerdmans, 2008.

Elliott, Neil. "Romans 13:1-7 in the Context of Imperial Propaganda", dalam Paul and Empire: On and Power in Roman Imperial Society, peny. Richard A. Horsley. Harrisburg, PA: Trinity Press International, 1997.

Harris, Geoffrey. Paul. London: SCM Press, 2009.

Jerome Murphy-O'Connor. "1 and 2 Corinthians", dalam The Cambridge Companion to St. Paul, peny. James D. G. Dunn. New York: Cambridge University Press, 2004.

Kieser, Bernard. "Melawan Fundamentalisme (Teologi) Katolik: Menemukan Gereja yang adalah Peristiwa, dalam Gereja yang Melayani dengan Rendah Hati, peny. E. Martasudjita. Yogyakarta: Kanisius, 2009.

Koester, Helmut. "Imperial Ideology and Paul's Eschatology in 1 Thessalonians", dalam Paul and Empire: On and Power in Roman Imperial Society, peny. Richard A. Horsley. Harrisburg, PA: Trinity Press University, 1997.

Landingham, Chris Van. Judgement and Justification in Early Judaism and the Apostle Paul. Peabody, MA: Hendrickson, 2006.

Lawson, John. Introduction to Christian Doctrine. Grand Rapids, MI: Francis Asbury, 1986.

Ridderbos, Herman. Paul: An Outline of His Theology, terj. John Richard De Witt. Grand Rapids, MI \& Cambridge, UK.:William B. Eerdmans, 1977.

Tambasco, Anthony J. A Theology of Atonement and Paul's Vision of Christianity. Collegeville, MN: The Liturgical Press, 1991.

Wright, N.T. Paul. Minneapolis: Fortress Press, 2005. 